This item was submitted to Loughborough's Research Repository by the author.

Items in Figshare are protected by copyright, with all rights reserved, unless otherwise indicated.

\title{
Experiences of ergonomics practitioners on vacation
}

PLEASE CITE THE PUBLISHED VERSION

LICENCE

CC BY-NC-ND 4.0

\section{REPOSITORY RECORD}

Maguire, Martin, C.A. Nicolle, Suzanne Lockyer, Magdalen Galley, Edward Elton, and Zaheer Osman. 2019. "Experiences of Ergonomics Practitioners on Vacation". figshare. https://hdl.handle.net/2134/909. 


\title{
EXPERIENCES OF ERGONOMICS PRACTITIONERS ON VACATION
}

\author{
Martin Maguire, Colette Nicolle, Suzanne Lockyer \\ Magdalen Galley, Edward Elton and Zaheer Osman \\ Ergonomics and Safety Research Institute (ESRI) \\ Loughborough University, Holywell Building, Holywell Way \\ Loughborough, Leics, LE11 3UZ, UK.
}

\begin{abstract}
A group of practitioners collaborated in reporting ergonomic issues experienced during their holidays. While poor ergonomics made a big impression on the vacationers, good well-designed aspects of their holidays demonstrate the benefits that ergonomics can bring.
\end{abstract}

\section{Introduction}

When on holiday, ergonomists sometimes find it difficult to "switch off”. Since their discipline is concerned with designing tools, products, equipment and systems to be fit for human use, this can apply as much to being on vacation as being at home or at work. What is distinctive about ergonomics applied to vacations? Firstly, hopes and expectations when going on holiday are usually high so encountering difficulties can cause disappointment. Also people try to relax on holiday so may be more easily caught out by poorly designed equipment. Furthermore, holidaymakers are often novice users of equipment, unaware that a balcony balustrade is too low to provide adequate protection, a deckchair is hazardous or that a beach umbrella will easily blow inside out. This paper describes recent experiences, both positive and negative, for a group of ergonomics practitioners at ESRI, Loughborough University.

\section{Holiday booking and documents}

Booking hotels and travel over the Internet is now popular since it allows users to explore different holidays and prices at their leisure. Yet while travel web-sites provide the basic details of the holiday resort and hotel, they often give insufficient background details about the country or local area, or relevant information such as currency and local transport information. It is also difficult to plan a touring holiday on a single website, or to track the itinerary or total cost of the holiday across several sites. Websites should also perhaps provide information about dangers when travelling to certain areas such as civil conflicts which would help to avoid situations such as the kidnapping of tourists and backpackers. Other risks that holiday makers might be unaware of should also be stated such as the dangerous traffic on South African roads every December when vast numbers take to the roads. On a positive note, holiday companies now streamline the documentation with flight tickets and other holiday documents coming in one booklet, with pages that are torn out when needed. Budget airlines streamline documentation still further by providing no ticket and just an email confirmation of a flight booking. Whether this is satisfactory may need further investigation.

\section{Airline travel}


Budget airlines offer travel at low cost with no frills. One author tried three UK-based budget airlines in one round trip from Luton to Zurich to Dublin and back to East Midlands Airport. On two of the airlines, seats were not allocated so passengers rushed to get to the front of the queue to get a good seat. For the third airline, which did allocate seats, boarding was a much calmer experience. Another author, travelling to Majorca, found that airport announcements were unclear and they also had to keep getting up to look at the display for the gate number (this was less of a problem at Heathrow where there were more displays placed strategically).

Boarding assistance for people who are heavily laden or who have young children should be provided. One airline recently told a passenger who was struggling with two young children, one in a pushchair, to ask other passengers if she needed help. One author found that they could not check in very early to get rid of cases. So at the restaurant she had to struggle with a food tray, hand luggage, a handbag and a suitcase on wheels. The Ladies toilet was found to have only one hand dryer working and this was blocked by a person washing her hands carefully, so that a queue of people formed. The toilet seat was also found to be very low which could be difficult for an older person with restricted movement.

Passengers often ignore the safety routine presented by cabin crew before take-off. Before presenting the procedures, the pilot or often crew remind the passengers to pay particular attention as some details (e.g. use of a lifejacket) could vary between aircraft. Safety films are commonly used on larger aircraft. A study at Loughborough (Page et al, 1996) of two different safety videos found that neither was wholly successful in increasing the risk perception of those who viewed them due to fatigue, intoxication or information overload. All of these factors need to be taken into account in developing safety videos.

Poor legroom on flights is a common problem and the cramped position of passengers has been cited as a reason for serious conditions such as deep vein thrombosis (DVT). The limited space experienced by one author was exacerbated by the passenger in-front reclining their seat and the neighbouring passengers 'stealing' the armrest. Recent reports of a device available in the USA to prevent other passengers from reclining their seats and therefore impinging on other's personal space could be a potential cause of 'air-rage'. In such circumstances, tasks such as eating a meal become very difficult. Watching the in-flight film was also hampered by glare on the screen from the cabin lights. One author was also surprised to find that when placing her reading glasses in the seat pocket, they dropped through. This was because the pocket was made up of a set of crossed straps, which is easier to clean than a simple, fully enclosed, pouch. The same author also finds when travelling from the United States, that landing cards are handed out early, allowing plenty of time for completion. However for short hops within Europe, she only gets a card just before coming in to land and so there is little time to complete it comfortably and legibly. Holiday company questionnaires handed out in-flight also seem to generate a poor response rate as they are often long and detailed, and come without a pen.

\section{Local transport}

Using local transport can be confusing for travellers from other countries. One author arrived in Zurich city centre on a Sunday and was faced with an unmanned ticket machine. It was not clear what ticket type or bus number was needed, and which direction bus they should take. As a result she had to walk to the local train station to get the information and a ticket, and then return to the stop. Having ticket machines in an unexpected place is also problematic. With the extension of the Eurostar rail link from Waterloo to St. Pancras/Kings Cross in London, the ticket machines have been moved out from the Underground station to outside the Kings Cross mainline station, which is confusing for unsuspecting travellers. However, one author arriving at Dublin airport found the bus service very traveller-friendly. A person was available near the 
bus stop area to direct passengers to the right bus and to take their luggage. On the bus itself, there was a display and audio announcements of the names of the bus stops and hotels nearby. These were presented well before the stop and were clear and personal.

Announcements of stops for all local transport are generally a good thing for all travellers and in particular for passengers who are blind. London Underground publishes a leaflet and a web-based interactive map that describes the accessibility of the different stations (see http://map.tfl.gov.uk/accessible/). Trams, a popular means of transport in much of Europe are also good for strangers to use for the same reason and have the added advantage of the view.

\section{Driving abroad}

Driving abroad is difficult for many people especially when they need to adapt to driving on a different side of the road. One Dutch project partner commented that drivers are more at risk of an accident when they return home and as they relax and forget which side to drive on. Unfamiliar road signs are also a problem. One visiting lecturer to Loughborough reported that, on some highways, lit-up traffic information signs in Rio de Janeiro had to compete with exotic signs advertising nightclubs and bars. An Irish colleague reported that during the national change over from miles to kilometres, two styles of speed limit sign were in operation (one in $\mathrm{mph}$ and the other in $\mathrm{kph}$ ) so that drivers needed to distinguish between the two. Hiring a vehicle abroad poses many problems, i.e. unfamiliar car, unfamiliar road network or jet-lagged driver. One conference speaker reported being impressed when arriving after dark at the rented car lot to find a small light integrated into the key fob, helping to identify the position of the lock.

\section{Hotels and other buildings}

Several authors commented about hotel rooms. In Crete it was found that the apartment's air conditioning was noisy at night and only worked when the balcony doors and windows were closed. Also, as the doors would not stay open, the author used a pair of shoes to hold them. Two authors experienced problems with keys and locks. One in Tunisia found that to lock his door when going out, he had to push in the central part of the lock mechanism, inside the room, and then pull the door closed behind him and there was nothing that indicated this procedure. To assist guests, one hotel in Interlaken had a demonstration lock at the reception desk. The author in Crete found that when trying to open their room door that they had opened their neighbour's apartment by mistake. Another author stated that she always judges the comfort of her room by the cleanliness and operability of the shower and the ability to move the showerhead up and down to avoid wet hair. She also needs a place to sit with plenty of light to make up. Often the only suitable place is in the bathroom sitting on the toilet seat or standing at the bathroom sink, holding a magnifying glass to aid her older eyes. To open the 'zesty lemon' soap packet on her recent trip, the author had to use her teeth. The packet urged the guest to 'restore your spirit' - although a taste of soap in the mouth was not the best start.

In a Majorcan hotel, the dinner trolleys in the hotel restaurant were big and cumbersome. This took two waitresses to push it when full and they struggled to push it between the tables, as there was insufficient space and guests had to continually move out of the way. Although intended for relaxation, sun beds can be uncomfortable and unsafe. One author found the plastic ridges on the sun bed dug into his back, so he was forced to buy an airbed to place on top of it. Another found that when lying on his front on the sun bed, and pushing himself up with his arms, this caused the front part of the bed to flip up suddenly and bump him on the head.

\section{Tourist facilities}


Facilities such as bank machines, information leaflets, and street signs are an important part of a successful holiday. Bank machines abroad now offer the convenience of access to local currency on the spot without having to bring a large amount into the country. However travellers will not know the exchange rate or how much the ATM commission charge will be until they return home. Bank machines usually present instructions in the customer's own language and the use of colour coded keys (red=cancel, yellow=clear, green=confirm) allow ease of cash withdrawal. One traveller in Turkey however had a problem due to lack of local experience. They tried to enter the amount required in millions by pressing the ' 0 ' key six times rather than " 000 " twice.

One author enjoyed a local road/train trip in Crete. However the lack of a commentary meant that limited information was conveyed. On a day long bus tour with British and German speaking passengers, the guide had so much information to convey that they were speaking in either one language or the other for most of the time which was tiring for all.

Another author, who visited a public building in Zurich, had trouble finding and accessing the ladies room as the chrome door matched the walls, making it look invisible. It was also so heavy to pull open that it appeared locked, while the door sign was engraved with black text so that it could hardly be seen. In Tunisia another author experienced a telephone, which was mounted so high up that it was hard to insert coins into (certainly inaccessible for a person in a wheelchair or someone of shorter stature). During the same holiday, on a quad bike safari across the desert, one member of the group had come with his young son of about 8 . The boy rode on the same bike as the expedition leader and was wearing his helmet. However on occasions the driver went on two wheels putting his young passenger in a dangerous position.

\section{Facilities for people who are disabled}

Everyone is entitled to an enjoyable holiday so providing facilities for people with disabilities is important. In Venice, stair lifts are provided so that people in wheelchairs can go over some of the numerous bridges in the city. Aircraft boarding arrangements for disabled passengers need careful thought and staff training. A report on the BBC Radio 4's "In Touch" programme (November 2003) told how one blind airline passenger asked for assistance to be led to the plane, only to be forced to sit in a wheelchair and be pushed across to the aircraft.

Many hotels now have rooms that are designed to be accessible by wheelchair. But this may simply mean that the guest can get through door and can turn around in the bedroom and bathroom. The bathroom should also have bars allowing the person to lift him or herself out of the wheelchair and onto the toilet seat. Wheelchair ramps to gain access to the building should not be too steep. A project partner, who is disabled, asked for a double room with a double bed for himself and his wife. Unfortunately, to create sufficient room for a wheelchair, the hotel provides a standard sized room and $3 / 4$ sized bed which was very uncomfortable for two people. He was able to get his portable hoist under the bed although this would not have been possible with a Divan bed. In another hotel, he was allocated the 'accessible room', which was located on the 6th floor. In the middle of the night there was a fire alarm. As guests are expected to evacuate the building without using the lift, this caused worry and concern until the alarm stopped without further incident. In contrast, his experience in an accessible room on the ground floor was much more positive because he knew that he could exit in an emergency.

\section{Dealing with an accident or illness}

Falling ill or suffering an accident on holiday can pose considerable problems. The husband of one of the authors broke his heal on holiday in Los Angeles. The company required the insured traveller to contact them before contacting a local doctor - not easy in an emergency. 
Unfortunately the emergency contact number printed in the insurance booklet was incorrect. Making arrangements required many telephone calls, but the author could not find any credit card phones that worked so had to use expensive hotel phones. Another problem was the time difference; the first emergency contact number (the wrong one) was in England, while the correct company was in Quebec. The next problem was to find the locations of hospitals and doctors, and knowing the procedure to follow when visiting them. (Language difficulties can be another problem although this was not so in this case.)

Part of the trip included a conference, which the author's partner was attending. Easy wheelchair hire meant that he could get around. They phoned the hire company (found in the local Yellow Pages), who took all the details and delivered the wheelchair directly to the hotel. It was difficult to get cash because the person in the wheelchair couldn't easily get out of the hotel to change traveller's cheques. They also required extra cash for taxis, and because they needed help, they had to give lots of tips. Taxi drivers were found to be helpful, but car boots had poor space, making it difficult to fit the wheelchair in (although the cars were large). The author also tried coaches, including the shuttle supplied to and from the conference, but the big steps proved to be a problem. The conference was located on three floors of a building with escalators, and only one small lift. The thick carpets in the building made wheeling the chair difficult. The disabled toilet was within the main toilet, so the wheelchair user had to negotiate two doors (one heavy and spring loaded). The cubicle was difficult to get into because of the narrow corridor with a tight turn. The soap, sink, and towels were inaccessible. Refreshment tables and tea urns were also difficult to get to.

On returning home, there was a difficulty in getting a luggage cart at the airport, which required money to be put in to release it. Although the need for rigorous procedures was appreciated, the security checks were found intimidating. The wheelchair user was asked if they could 'walk through' the x-ray machine. They were also subjected to a much closer search than normal (as the wheelchair and plaster could be used to hide objects) including a body search. The author was told to stand out of the way and not to assist her partner. The high point was the helpfulness of the car park staff on arrival who got their car ready and waiting although they returned 2 weeks early and only made contact on arrival at Heathrow.

\section{Conclusions and recommendations}

Despite the problems reported, the authors enjoyed their holidays although ergonomic issues did affect their perceptions of them. Designers and planners should appreciate that when a holidaymaker uses equipment or a service they are often a novice or casual user so intuitive design is important. Providing better information before travelling will help people on vacation to adjust to local conditions while obtaining accurate feedback from tourists will help identify ergonomic issues. Finally an unexpected good innovation or design feature will stay in a person's mind and help to create a positive impression of the whole holiday. Based on the findings of this paper, a list of recommendations is being prepared.

\section{Reference}

Page M., Southall, D., Bird, R. 1996, Critique of the Thomson holiday safety video on behalf of the Consumer Safety International, 16 July 1996, The Research Institute for Consumer Ergonomics (now part of ESRI), Loughborough University, Memo 1411.

\section{Acknowledgement}

The authors would like to thank Victoria Haines and Val Mitchell, of ESRI, for their inputs to this paper. 